\title{
A comestibilidade e outros mundos possíveis
}

\section{Edibility and other possible worlds}

Ana Claudia de Sá Teles Minnaert’

1 Doutoranda do Programa de Pós-graduação em Antropologia da Faculdade de Filosofia e Ciências Humanas da Universidade Federal da Bahia. Salvador, BA, Brasil.

Correspondência / Correspondence Ana Claudia de Sá Teles Minnaert E-mail:venegeroles@yahoo.com

\section{Resumo}

O objetivo deste artigo é discutir a ideia da comestibilidade, a partir de uma concepção ontológica de mundos, habitados por corpos que se relacionam entre si e com o universo em sua volta de maneiras diversas. Inicio a discussão com a contextualização da temática da comestibilidade na antropologia cultural, para então caracterizar o que pode ser denominado uma virada ontológica da antropologia, quando ela parte de uma abordagem epistemológica do mundo para uma apreensão ontológica de outros mundos possíveis. A discussão será embasada na compreensão dos termos worldview, associado à noção de cultura, e weltbild, associado à noção de ontologia. Terá como pano de fundo as ideias de Viveiros de Castro acerca do perspectivismo ameríndio e as de Roy Wagner, com seu processo de invenção das culturas.

Palavras-chave: Antropologia. Antropologia cultural. Cultura.

\section{Abstract}

The purpose of this article is to discuss the idea of edibility from an ontological conception of worlds inhabited by bodies that relate to each other and to the surrounding world in different ways. I will start the discussion by contextualizing the theme of edibility in Cultural Anthropology. Next, I will describe what can be referred to as an ontological change, as anthropology changes its epistemological approach to the world for an ontological 
apprehension of other possible worlds. The discussion will be grounded in understanding the terms worldview, associated with the notion of culture, and Weltbild, associated with the notion of ontology. This work is also backgrounded by the ideas of Viveiros de Castro, about Amerindian perspectivism, and Roy Wagner, with his process of "invention of culture".

Key words: Anthropology. Cultural Anthropology. Culture.

\section{A virada ontológica da comestibilidade}

A antropologia cultural considera a comestibilidade um processo simbólico, construído por uma rede de signos e significados que entrelaçam a comida, o comer e a relação dos indivíduos com os alimentos. Nessa perspectiva, a divisão do que é comestível ou não se baseia em uma divisão epistêmica, e não em uma base ontológica relacionada à relação do indivíduo com o mundo que o circunda. $\mathrm{O}$ alimento e o ato de comer são entendidos como uma representação, uma visão de mundo atrelada à forma como cada "povo" vê o mundo, relaciona-se com este e com os outros seres que nele habitam.

A alimentação é um tema complexo, pois articula o biológico, o social, o fisiológico e o imaginário. O livro A história da alimentação, organizado por Flandrin \& Montanari ${ }^{1}$, é iniciado com os seguintes questionamentos:

Em que, e a partir de quando, o homem se distingue do animal em sua alimentação? Pelo tipo de alimentos que consome ou por sua variedade? Pelo modo como os prepara antes de comê-los? Pela cerimônia que envolve seu consumo, a comensalidade e a função social que caracterizam as refeições?

Enquanto construção teórica, os sistemas alimentares têm sido usados para compreensão de grandes processos sociais, como o político-econômico, ${ }^{2}$ o simbólico, ${ }^{3} \mathrm{e}$ o de construção social da memória. ${ }^{4}$ Os estudos sobre alimentação constituem uma arena vital para o debate entre o materialismo cultural e o estruturalismo ou mesmo para dar explicações simbólicas para o comportamento humano ${ }^{5,6}$ ou refinar teorias acerca da relação entre evolução biológica e cultural. ${ }^{7}$

Segundo Geertz, ${ }^{8}$ a cultura envolve uma teia de significados, tecida pelo homem e na qual ele se encontra preso. A partir das ideias desse autor, as práticas alimentares podem ser compreendidas como uma construção histórica e cultural, associadas diretamente com a formação de um povo. 
Mas existiria apenas uma forma de ver o mundo ou vários mundos vistos pelos seres que neles habitam? O que varia é o próprio mundo ou a forma de vê-lo?

Para nós, ocidentais, são as visões do mundo que diferem, porém o mundo permanece igual a si mesmo. Contudo, para abordagens como a de Viveiros de Castro, a maneira de ver é sempre a mesma, ainda que passe de uma espécie para outra, pois o que muda é o próprio mundo.

Para os índios, muitas das doenças que os afligem são doenças provocadas por vingança dos animais comidos. Quando se come o corpo de um animal sem os cuidados necessários para não ofender seu espirito, este pode se vingar e nos devorar (por dentro, numa espécie de endocanibalismo aterrador). É preciso, portanto, ser sempre muito cauteloso quando se trata de comer. ${ }^{9}$

Assim, questiono, seria o comer apreendido da mesma forma para todos? Ao ingerir algo, todos os seres estabelecem com essa ação a mesma relação? A alimentação, enquanto articulação do biológico, do social, do fisiológico e do imaginário, não seria uma construção do mundo tal como eu o conheço? Teríamos liberdade de escolha em uma gama variada de opções na determinação do que é comestível ou não?

Inspirados por Viveiros de Castro, alguns antropólogos passaram a questionar se há apenas um mundo real, construído "culturalmente", ou vários mundos habitados por corpos distintos. Para eles, a antropologia, então centrada em uma visão epistêmica e não ontológica, vinha direcionando seus estudos em busca de representações que as outras pessoas tinham do mundo real e observava o mundo como algo único, visto a partir de visões de mundo distintas. ${ }^{9}$

Desta forma, a antropologia moderna, ao envolver o eu e o outro em um mesmo movimento de compreensão, não em busca de diferenças ou similaridades, mas na tentativa de compreender as condições sociais em que o pensamento opera, dá um salto ontológico, pois não busca mais apenas descrever noções, e sim apontar o que elas suportam e como elas funcionam na vida social. ${ }^{10}$

O termo ontologia é introduzido no discurso antropológico como oposto a cultura, apesar de alguns autores questionarem se é realmente um novo termo ou apenas outra palavra empregada com o mesmo significado. Candea ${ }^{11}$ diz que tanto cultura como ontologia são compreendidos de forma limitada, associados à mera representação, o que reduz os estudos culturais a simples estudos de significados e interpretações, da episteme das pessoas.

O que esse autor denomina "a virada ontológica da antropologia" surge no momento em que fugimos da redução da cultura como mera significação e nos percebemos da questão da diferença, da alteridade e da existência do outro, que tanto o termo cultura quanto o termo ontologia evocam. Pois, neste momento, restauramos o pleno potencial antropológico desses termos, estabelecido não apenas a partir de uma pluralidade de visões de mundo, mas com a compreensão da existência de uma multiplicidade de mundos reais. ${ }^{11}$ 
Nessa perspectiva, não há mundo pronto para ser visto, um mundo antes da visão, ou antes da divisão entre o visível (ou pensável) e o invisível (ou pressuposto) que institui o horizonte de um pensamento. Não se trata de propor uma interpretação da comestibilidade para quem come, mas de realizar uma experimentação com esse ente, como refere Roy Wagner: "[...] toda compreensão de uma outra cultura é um experimento com a nossa própria cultura”. ${ }^{2}$

O objetivo deste artigo é prestar novos ouvidos teóricos à ideia da comestibilidade, não a partir da busca das representações ou formas como pensamos o mundo, o comer e o alimento, ou seja, de uma visão de mundo (worldview), mas a partir de uma concepção ontológica de mundos distintos, habitados por corpos distintos, em busca da imagem desses mundos (weltbild) por quem os vivencia.

\section{Worldview e weltbild: o outro na antropologia}

Para Heidegger, ${ }^{13}$ o termo worldview só ganha sentido após Descartes, quando o sujeito passa a significar a essência do homem e o ente não humano passa a constituir um objeto para o sujeito humano, de modo que o ser torna-se reduzido à representatividade. Worldview é uma tentativa de tradução da palavra alemã Weltanschaung - welt (world) e anschaung (view) - e significa simplesmente perspectiva de mundo, visão de mundo, ou visão da vida, a partir da nossa posição no mundo, e relaciona-se, portanto, à experiência, à representação.

Na antropologia, worldview está atrelado à noção de cultura, e nos leva a uma aproximação epistemológica do mundo como único, habitado por seres que o percebem e veem de forma distinta. As análises worldview marcaram os estudos da antropologia da religião, da antropologia simbólica e da antropologia cultural.

Essa noção parte do pressuposto de que a mente é estruturada de maneira uniforme e que a variedade de culturas relaciona-se a momentos históricos, experiências, ideias e sentimentos distintos que interferem na forma de os indivíduos agirem e se relacionarem com o mundo e com os outros.

Beine $^{14}$ detectou que o termo worldview ainda é bastante recorrente, apesar de inúmeras críticas dos pós-modernistas. O seu uso tem sido limitado ao senso comum, sem uma concepção analítica, referindo-se à forma como as pessoas veem o mundo.

O perspectivismo ameríndio de Viveiros de Castro $^{15}$ vem questionar a utilização do termo worldview, ao nos mostrar que não é nossa visão de mundo que difere dos ditos "nativos", mas é o próprio mundo que muda. Para o autor, é o mundo do outro que muda e, para entendê-lo, devese sair do eu e ir na direção do outrem. Ele recusa uma explicação epistemológica do mundo e busca uma apreensão do outro no plano da imanência, na tentativa de não reduzir a antropologia "a uma série de ensaios etnossociológicos sobre visões de mundo." ${ }^{5}$ 
Prado Jr. ${ }^{16}$ comenta que, para Wittgenstein, weltbild e worldview são instâncias completamente diferentes. Com base nesse filósofo, ele define weltbild como o "amálgama de pseudo-proposições cristalizadas [sic] na base de um jogo de linguagem que, ao mesmo tempo, precede a alternativa entre o verdadeiro e o falso e abre o espaço para o seu advento, ou numa outra palavra, o plano onde se cruzam e se entrecocham os conceitos". Destarte, o weltbild encontra-se no plano da imanência e nos ajuda a vivenciar o caos, definindo um plano ou estilo de vida, sob o qual vivenciamos o mundo que se multiplica em worldviews.

No momento em que o homem, enquanto sujeito, deu ao seu viver o privilégio de ser o centro de todas as relações, a expressão "visão de mundo" passa a ser o nome para a posição do homem no meio do ente, que só é legítimo na experiência vivida (erlebnis). De acordo com Wittgenstein, para o homem moderno é necessário que tudo se torne experiência vivida, pois assim ele se apodera incondicionalmente de sua essência e a visão de mundo (worldview) passa a ser imagem (weltbild). No momento que mundo se transforma em imagem, a posição do homem se torna visão de mundo. ${ }^{16}$

Weltbild é um vocábulo muito utilizado pela tradição filosófica alemã (Kant, Nietzsche, Heidegger, Wittgenstein) para pensar a ontologia ou, especificamente, a relação entre o "ser" e o "mundo" ou a construção de mundos. ${ }^{16}$

Para Heidegger, ${ }^{13}$ o termo nasce da relação da experiência do ser com a sua ideia de vida e associase à ciência, a uma visão teórica do mundo externo, com o significado literal de imagem do mundo. Para este filósofo, a época moderna é a época do weltbild, pois nesse período há o que ele denomina um desendeusamento, isto é, a relação dos deuses passa de visão de mundo a uma vivencia religiosa.

A imagem do mundo (weltbild) não é uma representação, como worldview, é o próprio mundo. Conceber o mundo como imagem não significa apenas que o ente é representado, mas sobretudo que ele está diante de nós, em tudo que lhe pertence e em todas as suas conexões, como um sistema. ${ }^{13}$ Como aponta Drucker, ${ }^{17}$ "imagem é a representação apriorística que desde sempre já concebeu, definiu e reduziu toda novidade a um já sabido e concebido”.

Mas como a comestibilidade se delineia a partir das concepções de worldview e weltbild?

\section{A comestibilidade do outro}

A abordagem ontológica da comestibilidade nos leva a não mais olhar o comer a partir de uma visão de mundo, como uma representação de um conceito construído, mas apreender o mundo do outro, a fim de perceber o que é a sua ideia de comer e de alimento neste mundo. Tal abordagem trabalha a comestibilidade não a partir de oposições prévias, mas buscando associações ou vínculos que diferentes contextos, vistos como natureza-cultura, produzem mediante suas práticas e suas categorias. 
Viveiros de Castro ${ }^{18}$ salienta que o antropólogo é "alguém que discorre sobre o discurso de um "nativo", sendo discurso qualquer prática de sentido, cuja essência é a relação de sentido entre o discurso do antropólogo (o "observador") com o discurso do nativo (o "observado"). Ele supera a dicotomia entre ser e natureza e diz que não são distintas compreensões, pontos de vista ou worldviews sobre um mundo único, mas são distintos corpos, que habitam mundos distintos, com imagens de mundos, ou seja, weltbild, distintos para cada ente.

Ele analisa o alimento, o comestível e o não comestível para os yawalapiti, a partir do esboço da sua cosmologia, em que "somos o que comemos; mas também somos o oposto daquilo que comemos". ${ }^{18}$

[...] a comida humana por excelência é o peixe. Macacos e peixes opõem-se em outro eixo que macacos e onças: os peixes são os mais diferentes dos humanos, sendo assim o alimento característico destes; os macacos, os bichos mais parecidos conosco, são o alimento em situações "pré-alimentares", aquilo que se come quando ainda não se pode comer peixe..$^{18}$

Já os espíritos são sinal da incomestibilidade, pois causam doenças. Eles impõem formas variadas de abstinência alimentar ao doente e sua família, além de exigirem uma distribuição cerimonial de comida para a comunidade, levada a cabo pelos abstinentes. Muito ao contrário de se darem a comer, os espiritos começam por nos fazer não comer, e exigem em seguida que demos de comer, para que não sejamos, talvez, comidos por eles. ${ }^{18}$

Na culinária yawalapiti,

a ordem, do mais para o menos perigoso, assado, moqueado e cozido, ou seja, conforme a distância crescente do fogo. A comida cozida está associada às mulheres, que carregam a água; a menstruação de uma mulher estraga toda a comida cozida de sua casa, não a assada..$^{18}$

Viveiros de Castro ${ }^{18}$ analisa a classificação yawalapiti para categorizar os alimentos de acordo com seu modo de preparação. Para o autor, não é possível reduzir o sistema alimentar yawalapiti, como outras dimensões de sua cosmologia, a um dualismo natureza-cultura.

Em "O mármore e a murta: sobre a inconstância da alma selvagem" ${ }^{19} \mathrm{o}$ autor diz que, para os portugueses, os índios eram canibais, já, para os índios "a prática do canibalismo tinha um peso diferenciado no sistema guerreiro dos Tupi e Guarani da costa". Ele nos traz a importância de compreender o canibalismo a partir de diversas perspectivas, a da vítima, a dos índios e a dos devoradores. Assim, o canibalismo (constructo) deve ser analisado a partir dos diversos mundos em que se inscreve. 
O autor nos leva a transcender do eu para o outrem, numa viagem a outros mundos, a fim de apreender os perceptos deste mundo, aceitando-os como simétricos aos nossos, sem qualquer valorização ou hierarquização, para entender os conceitos, onde eles são construídos, para então aplicá-los.

Para Deleuze, ${ }^{20}$ nós não estamos simplesmente no mundo, mas tornamo-nos com o mundo, contemplando-o. Para ele, não conheceremos nada mediante conceitos se não os criamos inicialmente em um campo, um solo que abrigará seus germes, seus personagens.

Para esse filósofo, é o outrem, em seu conceito, a condição de toda percepção, "a condição sob a qual passamos de um mundo a outro", tanto para os outros quanto para nós.

Com efeito, se nós o identificarmos a um objeto especial, outrem já não é outra coisa senão o outro sujeito, tal como ele aparece para mim; e se nós o identificarmos a um outro sujeito, sou eu que sou outrem, tal como eu the apareço. ${ }^{20}$

Destarte, considerar a diferença entre os mundos como uma diferença cultural é algo bastante superficial, é reduzir a cultura a mera significação. Para entender a cosmologia yawalapiti, Viveiros de Castro ${ }^{18}$ formulou um esboço dessa cosmologia, para então compreender o mundo na perspectiva de quem o vive.

A comestibilidade é um conceito visto a partir de um worldview, em que ela se inscreve associada ao ato de alimentar, à nutrição, ao prazer. Mas observar o nativo, a partir dessa ideia, é limitá-lo a um worldview, como se meu mundo fosse único e real. Devo me libertar dos conceitos e refletir a respeito do sentido do ser, com a possibilidade de múltiplas existências, devo transcender para uma esfera onde outros mundos coexistem, habitados por outros corpos que se relacionam entre si e com o mundo de maneiras diversas. Como diz Viveiros de Castro, devo buscar interseções entre a experiência cotidiana e a esfera das coisas. ${ }^{19}$

Na minha visão de mundo, gato é gato, cachorro é cachorro, comestível é o que alimenta meu corpo e a isso segue uma classificação que afasta o alimento do meu campo afetivo e do que estabeleço como humanidade. No mundo que vivencio, que experimento, no meu worldview, gato e cachorro são companhias, próximas à humanidade, com quem estabeleço uma relação de afetividade, e comê-los é um ato próximo ao canibalismo. Um peixe é alimento, mas o peixe que crio em aquário, dou comida, converso e assim "humanizo” não é mais comida. O alimento é o que nutre meu corpo, aguça meus sentidos, me dá prazer, saúde ou doença e o que está afastado da minha noção de humanidade.

Ao buscar entender a comestibilidade, eu busco compreender algo vivenciado a partir de uma perspectiva minha, do comestível e do não comestível, mantenho uma visão binária do mundo. Contudo, existem outros mundos, onde a própria comestibilidade possa estar associada à ideias 
distintas e inscrita como uma construção completamente diversa da que utilizo para compreender o comestível para doentes, para aos fracos, para as cerimônias, para o trabalho.

Como refere Oliveira, ${ }^{21}$ "ao invés do eu, é outrem quem estrutura e torna a percepção possível, como um verdadeiro princípio a priori de organização de todo campo perceptivo”. E esse outrem deve ser entendido como uma condição de passagem de um mundo possível a outro.

\section{A invenção antropológica de outros mundos}

Roy Wagner"12 afirma que a antropologia "estuda o fenômeno do homem - a mente do homem, seu corpo, sua evolução, origens, instrumentos, arte ou grupos, não simplesmente em si mesmos, mas como elementos ou aspectos de um padrão geral ou de um todo”.

Para o autor, "o antropólogo experiencia, de um modo ou de outro, seu objeto de estudo; ele o faz através do universo de seus próprios significados para comunicar uma compreensão aos membros de sua própria cultura", ${ }^{12}$ assim o seu conhecimento é baseado na profundidade e no entendimento que tem da cultura estudada, cultura essa que passa a ser visível à medida que é conhecida, ou, como refere o autor, inventada.

Ele $^{12}$ diz que, no ato de inventar outra cultura, o antropólogo inventa não apenas a sua própria cultura como também reinventa a própria noção de cultura. A percepção e a compreensão do outro ocorre a partir de uma espécie de analogia, uma extensão do que me é familiar para o entendimento do outro. Assim, para entender o comestível para determinado grupo, utilizo a minha compreensão de comestibilidade, analiso as coisas, os comportamentos a partir dessa compreensão, da minha visão de mundo.

Wagner diz: "plausível é uma função do ponto de vista do observador, a 'cultura' que ele imagina para o nativo está fadada a manter uma distinta relação com aquela que ele reivindica para si mesmo". ${ }^{2}$

Ao inventar a cultura chinesa, por exemplo, na qual comer cachorro é algo culturalmente explicado, mantenho uma distinção entre o eu e o outro, e invento uma cultura, como uma coisa plausível de ser feita, simbolizando as relações sociais, como o ato de comer, para então buscar compreendê-lo. Invento uma cultura, a partir de uma base de comunicação em convenções compartilhadas para tornar o outro inteligível, compreensível na minha visão de mundo.

O meu "mundo possível" - onde comestível e não comestível relacionam-se, dentre outros fatores, com a minha associação com humanidade - é sustentado por bases científicas, por conceitos que me ajudam a organizar o caos e me impedem de perceber outras lógicas ou situações insuspeitadas neste meu mundo. Ao analisar antropologicamente o "outro", tomando como pressuposto essa minha concepção de mundo, corro o risco de limitar as possibilidades de apreensão de outros mundos. 
Para Viveiros de Castro, ${ }^{19}$ nesse contexto, o outrem surge como "a condição do campo perceptivo”, e não um elemento desse campo.

[...] outrem não é, portanto, um ponto de vista particular, relativo ao sujeito (o "ponto de vista do outro" em relação ao meu ponto de vista ou vice-versa), mas a possibilidade de que haja ponto de vista - ou seja, é o conceito de ponto de vista. Ele é o ponto de vista que permite que o Eu e o Outro ascendam a um ponto de vista.

Destarte, os estudos sobre comestibilidade devem conceder ao outro sua posição de outrem, não o apreendendo como um "robô", alguém que vive no mundo sem refletir sobre ele, sem construir teorias que deem conta do caos, sem um ordenamento que dê sentido a sua existência, sem uma compreensão de si e do outro, alguém que vive irrefletidamente. $\mathrm{O}$ antropólogo, assim como o xamã, deve visualizar os mundos que se perpassam a partir do olhar dos seres que nele coabitam.

Concordo com os autores quando eles trazem e reconhecem o discurso nativo sobre o mundo com o mesmo valor científico que o discurso antropológico e reconhecem nas categorias nativas o estatuto de categorias analíticas, pois só a partir dessa compreensão é que os antropólogos estarão de fato estabelecendo uma relação de sentido entre o seu discurso e o discurso do nativo.

A comestibilidade não está restrita a padrões culturais, amontoados e ordenados por símbolos significativos, nos quais os indivíduos buscam sentido para os acontecimentos que vivenciam, mas envolve a reflexão acerca do sentido abrangente do ser, em suas múltiplas existências. Compreender o alimento e o ato de comer como mera representação é não reconhecer ao outro (que come) sua condição de sujeito, sua condição de outrem, enquanto expressão de um mundo possível.

\section{Referências}

1. Flandrin JL, Montanari M. História da Alimentação. 6 ed. São Paulo: Estação Liberdade; 1998. 885 p.

2. Mintz WS. Sweetness and power: the place of sugar in Modern History. New York: Penguin Books; 1986. 274 p.

3. Munn ND. The fame of Gawa: a symbolic study of value transformation in a Massin (Papa New Guinea) Society. Cambridge, UK: Cambridge Univ. Press; 1986. 333 p.

4. Sutton D, Beriss D. Restaurants, ideal Postmoderm institutions. In: Sutton D, Beriss D. The restaurants book: ethnographies of where we eat. Oxford; New York: Berg; 2007. 1-23 p.

5. Harris M. Bueno para comer: enigmas de alimentación y cultura. 3. ed. Madrid: Alianza Editorial; 2011. $390 \mathrm{p}$.

6. Gade DW. Nature and culture in the Andes. Madison: Univ. Wis. Press; 1999. 312 p.

7. Mintz SW, Du Bois CM. The Anthropology of food and eating. In: Annual Review Anthropology; 2002. V. 31, p. 99-119. 
8. Geertz C. A interpretação das culturas. Rio de Janeiro: LTC; 1989. 214 p.

9. Sztutman R (orgs.). Viveiros de Castro. Rio de Janeiro: Beco do Azougue Editorial; 2007. 263 p. (Encontros).

10. Giumbelli E. Os azande e nós: experimento de antropologia simerica. Horiz. Antropol. 2006 jundez;12(26):261-397.

11. Candea M et al. Ontology is just another word for culture: motion table at 2008. Meeting of the Group for Debates in Anthropological Theory (GDAT), University of Manchester; 2008. Disponível em: http://www.socialsciences.manchester.ac.uk/disciplines/socialanthropology/research/gdat/ documents/2008\%20Ontology $\% 20$ just $\% 20$ another $\% 20$ word $\% 20$ for $\% 20$ culture.pdf

12. Wagner R. A invenção da Cultura. São Paulo: Cosac Naify; 2010. 253 p.

13. Inwood M A. Heidegger dictionary. Oxford, UK: Blackwell Publisher; 1999. 283 p.

14. Beine D. The end of worldview in Anthropology? SIL Eletronic Workers Papers; 2010. Disponível em: http://www-01.sil.org/silewp/2010/silewp2010-004.pdf

15. Viveiros de Castro E. O Nativo relativo. Mana. 2002 abr;8:113-48.

16. Prado Jr B. Erro, ilusão, loucura: ensaios. São Paulo: Ed. 34; 2004. 280 p.

17. Drucker C. Tarde demais para os deuses: três características de uma perspectiva ser- historial sobre a religião. Nat hum. 2009 fev;11(2). Disponível em: http://pepsic.bvsalud.org/scielo.php?pid=S1517 24302009000200006\&script=sci_arttext

18. Viveiros de Casto E. A inconstância da alma selvagem: e outros ensaios de antropologia. São Paulo: Cosac Naif; 2002. 552 p.

19. Viveiros de Castro E. O mármore e a murta: sobre a inconstância da alma selvagem. Rev Antropol. 1992;35:21-74.

20. Deleuze G, Guattari F. O que é Filosofia. 2. ed. Rio de Janeiro: Ed. 34; 1996. 279 p.

21. Oliveira FCB de. A estrutura outrem no processo de conhecimento de outros mundos possíveis. RBSE. 2007 abr;6(16):156-83. Disponível em: http://www.cchla.ufpb.br/rbse/RBSE206\%2816\%29\%20 Abril $\% 20$ de $\% 202007$.pdf

Recebido: 25/5/2013

Aprovado: 15/8/2013 